\title{
The novel application of artificial neural network on bioelectrical impedance analysis to assess the body composition in elderly
}

\author{
Kuen-Chang Hsieh ${ }^{1 \dagger}$, Yu-Jen Chen ${ }^{2+}$, Hsueh-Kuan Lu ${ }^{3}$, Ling-Chun Lee ${ }^{4}$, Yong-Cheng Huang ${ }^{5}$ and Yu-Yawn Chen ${ }^{5^{*}}$
}

\begin{abstract}
Background: This study aims to improve accuracy of Bioelectrical Impedance Analysis (BIA) prediction equations for estimating fat free mass (FFM) of the elderly by using non-linear Back Propagation Artificial Neural Network (BP-ANN) model and to compare the predictive accuracy with the linear regression model by using energy dual X-ray absorptiometry (DXA) as reference method.
\end{abstract}

Methods: A total of 88 Taiwanese elderly adults were recruited in this study as subjects. Linear regression equations and BP-ANN prediction equation were developed using impedances and other anthropometrics for predicting the reference FFM measured by DXA (FFM $M_{D X A}$ ) in 36 male and 26 female Taiwanese elderly adults. The FFM estimated by BIA prediction equations using traditional linear regression model (FFM $\mathrm{LR}_{\mathrm{R}}$ ) and $\mathrm{BP}-\mathrm{ANN}$ model $\left(F_{F M} M_{A N N}\right)$ were compared to the FFM $M_{D X A}$. The measuring results of an additional 26 elderly adults were used to validate than accuracy of the predictive models.

Results: The results showed the significant predictors were impedance, gender, age, height and weight in developed FFM $L$ linear model (LR) for predicting FFM (coefficient of determination, $r^{2}=0.940$; standard error of estimate $(\mathrm{SEE})=2.729 \mathrm{~kg}$; root mean square error $(\mathrm{RMSE})=2.571 \mathrm{~kg}, P<0.001)$. The above predictors were set as the variables of the input layer by using five neurons in the BP-ANN model $\left(r^{2}=0.987\right.$ with a SD $=1.192 \mathrm{~kg}$ and relatively lower RMSE $=1.183 \mathrm{~kg}$ ), which had greater (improved) accuracy for estimating FFM when compared with linear model. The results showed a better agreement existed between FFM $M_{A N N}$ and FFM $M_{D X A}$ than that between FFM $M_{L R}$ and $F F M_{D X A}$.

Conclusion: When compared the performance of developed prediction equations for estimating reference FFM $\mathrm{DXA}_{\mathrm{A}}$ the linear model has lower $r^{2}$ with a larger SD in predictive results than that of BP-ANN model, which indicated ANN model is more suitable for estimating FFM.

Keywords: Back Propagation Artificial Neural Network (BP-ANN), Body composition, Bioelectrical impedance analysis (BIA), Elderly, Dual-energy X-ray absorptiometry

\section{Background}

Body composition is routinely measured to evaluate the nutritional status of patients in clinical setting. The prognosis of morbidity and mortality in the elderly are strongly associated with nutritional status $[1,2]$. In the elderly, the fat mass (FM) decreases with age [3] and differences in gender become prevalent [4]. The assessment

\footnotetext{
* Correspondence: yu11.tw@yahoo.com.tw

${ }^{\dagger}$ Equal contributors

${ }^{5}$ Department of Physical Education, National Taiwan University of Physical Education and Sport, 16, Sec. 1, Shuan-Shih Rd, Taichung 40404, Taiwan
} Full list of author information is available at the end of the article results of body composition can be used to prevent malnutrition, monitor health risks, design physical therapy programs, facilitate the improvement of heath programs [5] and predict drug kinetics in the elderly [6]. Therefore, the accuracy and precision of the measuring results in the elderly will be critical in clinical application.

Currently, many body composition measurements are limited in their applications to the elderly. The noninvasive, simple, safe, fast and inexpensive properties of bioelectrical impedance analysis (BIA) make this method an applicable measurement for the elderly [7]. 
The measurement of body composition using BIA oftentimes includes many predictive variables, such as impedance, ethnicities, age, sex, height and weight to develop linear prediction equations for estimating body fat content [8].

Despite the fact that the standing hand-to-foot BIA is more convenient than the supine hand-to-foot BIA [9], the standing hand-to-foot BIA has not yet been widely used except for limited reports in the current research literature [10]. The simple operational procedure for conducting a standing hand-to-foot BIA measurement can efficiently measure body composition in clinical application and epidemiological researches [11]. The impedance measured by BIA can incorporate with other predictive variables, such as age, sex, activity levels and ethnicities to develop a prediction equation, if the estimated results are validated by DXA can provide a relatively accurate estimation of body composition, especially using standing hand-to-foot BIA method [12]. Furthermore, some populations possess specific physiological characteristics such as the obese subjects [13], adolescents [14], young women with high physical activity levels [15] and elite male athletes [16] may require a specific developed BIA prediction equation for obtaining more accurate estimates. The existing published BIA equations were developed through linear regression analysis by using independent variables such as height, weight, sex, age and impedance [7]. The above rationale assumed that the relationship between the independent variables and dependent variable exhibits a linear relationship rather than non-linear relationship [17].

The linear regression model was used to describe the relationship between a single dependent variable such as FFM and other independent variables such as impedance, height, age, weight and sex. While the linear regression model may appear to be simple and applicable; however, when choose several variables as predictors to construct a multivariable regression model which may violate the basic assumption about independence of explanatory variables from one another. Since anthropometric variables often correlated with each other, the colinearty can lead to mistaken conclusions. Therefore, the linear regression model may not be a suitable method for developing a prediction equation. The results of previous BIA studies in elderly adults have shown that the association between anthropometric variables and body composition parameters were not very strong [18]; therefore, an improvement of prediction equation is needed.

Other prediction models, including logistic regression [19], Cox regression [20], discriminant analysis, recursive partitioning [21] and artificial neural network-ANN [22], have been widely used in clinical applications for diagnosis [23], imaging [24], the analysis of wave forms [25], the identification of pathological specimens [26], clinical pharmacology [27] and outcome prediction [28,29]. Two studies had utilized the BIA measurements with an ANN model to evaluate the intracellular fluid [30] and total water body in patients under chronic hemodialysis [31]. The results of these two studies showed that ANN model performed better in predictive accuracy than a linear regression analysis did [30,31]. Very few studies have investigated the measurement of whole body composition, lean body mass and skeleton muscle mass using BIA measurement with ANN analysis. Whether the ANN model exhibits greater precision and accuracy in BIA measurement than the linear model is an interesting issue.

In the present study, we measured the FFM of Taiwanese male and female elderly adults using both BIA and DXA to develop a Back Propagation - Artificial Neural Network (BP-ANN) predictive model and compared the results with those of the linear predictive model to evaluate whether the ANN model exhibits greater accuracy.

\section{Methods}

\section{Subjects}

Healthy elderly subjects age 55 and over without chronic diseases such as hypertension, diabetes mellitus, cancer, nephrotic syndrome, hepatitis-related disease, chronic pulmonary disease, or artificial electrical implantation and assist devices, were recruited with the permission of the Institutional Review Board (IRB) of the Advisory Committee at Jen-Ai Hospital in Taiwan. 48 elderly males and 40 elderly females from central Taiwan were informed with formal consent forms prior test. The 62 randomly sampled subjects used to develop the BP-ANN mathematical model for the estimation of FFM were called the modeling group (MG), and the remaining 26 subjects comprised the validation group (VG).

\section{Experimental procedures}

The body weight and height of the subjects were measured to the nearest $0.1 \mathrm{~kg}$ and $0.5 \mathrm{~cm}$, respectively. All of the subjects were dressed in cotton robe without any metal attachments for the whole body DXA (Lunar Prodigy, GE Corp, USA.) measurements. The results were analyzed with "enCore 2003 Version 7.0" software. The whole body scanning protocol of each subject was completed within twenty minutes. All measurements were conducted by licensed technicians in the Radiology Department of the Dah Li County Jen-Ai Hospital in Taiwan. The FM and FFM were estimated by DXA. After DXA measurements, the subjects stood on a platform embedded with tetra-polar electrodes and gripped a handle embedded with bi-polar electrodes on the right hand side to measure the impedance at a frequency of $50 \mathrm{kHz}$. The impedance measurement instrument (QuadScan 4000; Bodystat, Ltd., Isle of Man, UK) contains independent detect electrodes 
and current source electrodes in the platform and handle grip. The total FFM values estimated by BIA using linear regression analysis $\left(\mathrm{FFM}_{\mathrm{LR}}\right)$ or by BIA using BP-ANN model analysis $\left(\mathrm{FFM}_{\mathrm{ANN}}\right)$ were compared to the DXA measurement $\left(\mathrm{FFM}_{\mathrm{DXA}}\right)$.

\section{Back propagation-artificial neural network (BP-ANN)}

We created the FFM predicting model using the BP-ANN (Figure 1), including an input layer, hidden layer and output layer [32]. The input layer contained $\mathbf{p}_{\mathbf{j}}(\boldsymbol{j}=1$ to 5 ) values, including height $(\mathrm{h})$, weight $(\mathrm{m})$, age $(\mathrm{y})$, impedance $(\mathrm{Z})$ and sex $(\mathrm{S})$. The hidden layer contained the one to multiple neurons that combine both the $\mathbf{W}_{\mathrm{i}, \mathrm{j}}^{1}$ (weight matrix) and $\mathbf{b}_{i}^{1}$ (bias vector). In other words, the calculation of the input value using both the $\mathbf{W}_{\mathrm{i}, \mathrm{j}}^{1}$ and $\mathbf{b}_{\mathrm{i}}^{1}$ gave the $\mathbf{n}_{\mathrm{i}}^{1}$ value, which was subsequently substituted into $\mathbf{f}^{1}$ (transfer function), which is the Log-Sigmoid function, to determine the $\mathbf{a}_{\mathrm{i}}^{1}$. The $\mathbf{a}_{\mathrm{i}}^{1}$ was termed the first hidden layer. The above equations can be expressed as follows:

$$
\begin{aligned}
\mathbf{a}^{1}{ }_{i} & =\mathbf{f}^{1}\left(\mathbf{W}^{1}{ }_{i, j} \mathbf{p}_{j}+\mathbf{b}^{1}{ }_{i}\right)=\mathbf{f}^{1}\left(\mathbf{n}^{1}{ }_{i}\right) \\
& =\log \sin \left(\mathbf{W}^{1}{ }_{i, j} \mathbf{p}_{\mathbf{j}}+\mathbf{b}^{1}{ }_{i}\right)
\end{aligned}
$$

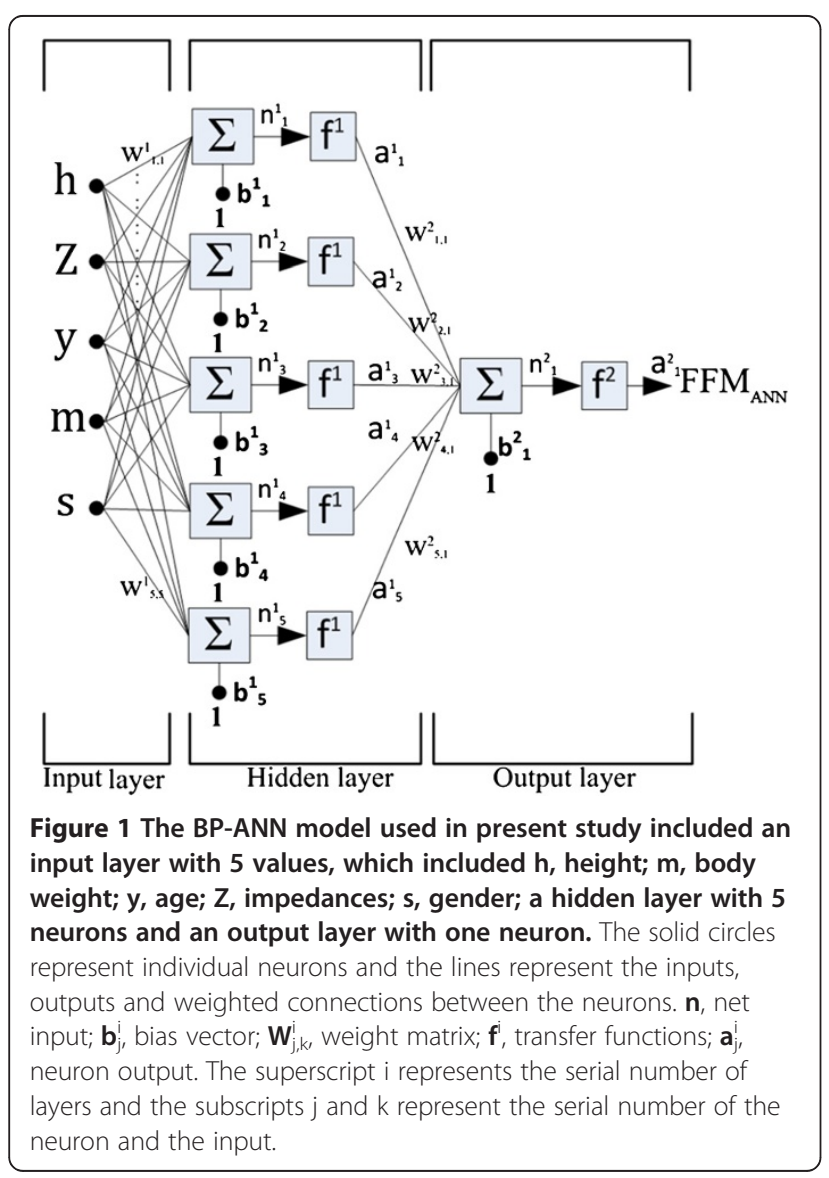

$\log \sin (\mathrm{n})=1 /\left(1+e^{-n}\right)$

Scalars - small italic letters

Vectors - small bold non-italic letters

Matrices - capital BOLD non-italic letters

$\mathrm{i}$-the series number of the neuron

$\mathrm{j}$-the number of input values $\left(\mathbf{p}_{1}=\mathrm{h}, \mathbf{p}_{2}=\mathrm{w}, \mathbf{p}_{3}=\mathrm{y}\right.$, $\left.\mathbf{p}_{4}=\mathrm{Z}, \mathbf{p}_{5}=\mathrm{s}\right)$

The outcome value $\mathbf{a}^{\mathbf{1}}$ is connected to the output layer, which contains $\mathbf{f}^{2}$ (Linear transfer function). The above equation can be expressed as follows:

$$
\begin{aligned}
\mathbf{a}^{2} & =\mathbf{f}^{2}\left(\mathbf{W}^{2}{ }_{i, 1} \mathbf{a}_{i}{ }_{i}+\mathbf{b}^{2}{ }_{1}\right)=\mathbf{f}^{2}\left(\mathbf{n}^{2}{ }_{1}\right) \\
& =\operatorname{purelin}\left(\mathbf{W}^{2}{ }_{i, 1} \mathbf{a}^{1}{ }_{i}+\mathbf{b}^{2}{ }_{1}\right)
\end{aligned}
$$

$\operatorname{purelin}(\mathrm{n})=\mathrm{n}$

The output layer with a single hidden layer in the present BP-ANN model can be expressed as follows:

$$
\begin{aligned}
\mathbf{a}^{2}{ }_{1}= & \left.\mathbf{f}^{2}\left(\mathbf{W}^{2}{ }_{i, 1} \mathbf{f}^{1}\left(\mathbf{W}^{1}{ }_{i, j} \mathbf{p}_{j}+\mathbf{b}^{1}{ }_{i}\right)\right)+\mathbf{b}^{2}{ }_{1}\right) \\
= & \operatorname{purelin}\left(\mathbf{W}^{2}{ }_{i, 1} \log \sin \left(\mathbf{W}^{1}{ }_{i, j} \mathbf{p}_{j}+\mathbf{b}^{1}{ }_{i}\right)+\mathbf{b}^{2}{ }_{1}\right) \\
& \times(i=1 \text { to } 5, \mathbf{j}=1 \text { to } 5)
\end{aligned}
$$

During the first training procedure, all of the anthropometric $\mathbf{p}_{\mathbf{j}}$ values, which contain height, weight, age, sex and impedances, in the input layer were randomly weighted for each equation in the initial weight matrix as $\mathbf{W}_{\mathrm{i}, \mathrm{j}}^{1}, \mathbf{W}_{\mathrm{i}, 1}^{2}$, with the addition of the initial values in the bias vector as $\mathbf{b}_{i}^{1}, \mathbf{b}_{1}^{2}$. The target $\mathbf{t}$ FFM values were measured by a DXA. After comparing to the target $\mathbf{t}$ values, the network applied the Levenberg-Marquardt algorithm to optimize the bias vector and weight matrix, subsequently processing the data backward to repeatedly adjust the weight matrix and bias vectors until convergence. For the training rule in the present study, we set the maximum iteration as 1000 times, with a minimum gradient value of $10^{-6}$. All of the algorithms mentioned above were coded by Matlab Ver.7.0 (MathWorks, Inc. MA, USA). The BP-ANN models containing one to five neurons were created in the hidden layer to explore the effects of neuron number on the precision of FFM prediction. After the training process, the optimal weight matrix of the $\mathbf{W}_{\mathrm{i}, \mathrm{j}}^{1}$ and $\mathbf{W}_{\mathrm{i}, 1}^{2}$ variables and the bias vector of the $\mathbf{b}_{\mathbf{i}}^{1}$ and $\mathbf{b}_{1}^{2}$ variables were obtained.

\section{Statistical analysis}

All of the data were analyzed by SPSS version14.0 software (SPSS Inc., Chicago, IL, USA). The data are presented as the means \pm standard deviation (SD). The data of 62 randomly sampled subjects were used to develop the BPANN model and linear regression model for predicting FFM. Multivariable linear regression was used to develop 
a linear FFM prediction equation for comparison with the ANN equation. The $\mathrm{FFM}_{\mathrm{LR}}$ and $\mathrm{FFM}_{\mathrm{ANN}}$ were compared with each other by using Bland and Altman plots in which the predictive results in each subject by both equations were plotted against reference $\mathrm{FFM}_{\mathrm{DXA}}$; the differences in predicting $\mathrm{BF} \%$ were also compared. The standard error of estimate (SEE) and root-mean-square error (RMSE) were also used to measure the accuracy of predictions. The coefficient of determination $\left(\mathrm{r}^{2}\right)$ were calculated to compare the goodness of fit between two models. Also, the data of an additional 26 subjects were used to validate the developed equations. For all statistical analyses, a $\mathrm{P}$ value of $<0.05$ was considered significant.

\section{Results}

The basic characteristics and body composition data for the MG and VG are shown in Table 1. The mean age of the males and females in the MG group was $61.0 \pm 5.14$ years and $61.2 \pm 5.8$ years, respectively, while the mean body fat content of the male and female subjects was $27.0 \pm 5.3 \%$ and $35.8 \pm 6.7 \%$, respectively. The mean age of the males and females in the VG group was $65.1 \pm 5.0$ years and $61.3 \pm 5.07$ years, respectively, while the mean body fat content was $27.0 \pm 5.3 \%$ and $35.8 \pm 6.7 \%$, respectively.

The linear prediction equation was obtained by linear regression analysis, height $(\mathrm{h})$, weight $(\mathrm{m})$, age $(\mathrm{y})$, sex ( $\mathrm{S}, 1$ : male, 0: female) and impedances were set as independent variables, and the FFM measured by DXA was set as dependent variables.
$\mathrm{FFM}_{\mathrm{LR}}(\mathrm{kg})=7.104+2.433 S+0.719 h^{2} / Z+0.217 m-0.183 y$ $\left(r^{2}=0.940\right.$, standard error of estimate $\left.(\mathrm{SEE})=2.729 \mathrm{~kg}, P<0.001\right)$

During the training process, the hidden layers containing one to five neuron units in the BP-ANN model were executed with starting values of 1000 by the optimal algorithms (Levenberg-Marquardt (L-M) or Bayesian Regularization (B-R)) separately to obtain the optimal weight matrix $\mathbf{W}_{\mathrm{i}, \mathrm{j}}^{1}, \mathbf{W}_{\mathrm{i}, 1}^{2}$ and bias vector $\mathbf{b}_{\mathrm{i}}^{1}, \mathbf{b}_{1}^{2}$. The $\mathbf{p}_{\mathbf{j}}$ values were substituted into the optimal BP-ANN model to obtain the estimated FFM $_{\mathrm{ANN}}$ values. The effect of the number of neurons in the input layer on the determination coefficients of the FFM ${ }_{\text {DXA }}$ in the BP-ANN model is shown in Figure 2.

The highest coefficients of determination $\left(\mathrm{r}^{2}=0.987\right)$ occurred with five neurons in the predictive model; however, the highest coefficients of determination at one neuron unit still measured up to $\mathrm{r}^{2}=0.960$. We re-substituted the anthropometric and impedance values into the optimal BPANN model with five neurons to estimate the $\mathrm{FFM}_{\mathrm{ANN}}$. The coefficient of determination of the estimated FFM $_{\mathrm{ANN}}$ vs. FFM ${ }_{\text {DXA }}$ reached up to $\mathrm{r}^{2}=0.987$ with the L-M algorithm and $\mathrm{r}^{2}=0.971$ with the B-R algorithm (Figure 3).

The Bland-Altman plot of bias in each predictive FFM value from both of the developed predictive equations is shown in Figure 4a The limits of agreement for estimated $\mathrm{FFM}_{\mathrm{LR}}$ vs. FFM DXA were $\pm 5.183 \mathrm{~kg}$ at $2 \mathrm{SD}$, while the

Table 1 The basic characteristics and body composition data of the subjects

\begin{tabular}{|c|c|c|c|c|}
\hline & Mean \pm SD & Range & Mean \pm SD & Range \\
\hline M.G. ${ }^{1}$ & Male & $(n=36)$ & Female & $(n=26)$ \\
\hline Age (years) & $60.99 \pm 5.14$ & $55.0,71$ & $61.2 \pm 5.8$ & $55.0,74.8$ \\
\hline Height (m) & $1.69 \pm 0.08$ & $1.50,1.91$ & $1.57 \pm 0.06$ & $1.46,1.76$ \\
\hline Weight (Kg) & $73.8 \pm 13.6$ & $53.8,114.4$ & $61.8 \pm 9.2$ & $42.0,79.7$ \\
\hline $\mathrm{BMI}\left(\mathrm{Kg} / \mathrm{m}^{2}\right)$ & $25.8 \pm 3.8$ & $20.3,36.8$ & $25.0 \pm 3.9$ & $17.9,35.4$ \\
\hline Impedance (ohm) & $545.4 \pm 60.4$ & $407.6,774.3$ & $639.8 \pm 61.8$ & $479.2,777.0$ \\
\hline FFM $_{\text {DXA }}(\mathrm{kg})^{3}$ & $52.7 \pm 9.3$ & $28.0,79.1$ & $37.3 \pm 4.6$ & $29.7,44.9$ \\
\hline $\mathrm{FM}_{\text {DXA }}(\mathrm{kg})^{3}$ & $21.1 \pm 7.9$ & $4.5,37.9$ & $24.4 \pm 7.1$ & $10.7,38.3$ \\
\hline BF\% ${ }_{D X A}(\%)^{3}$ & $28.2 \pm 8.0$ & $6.2,49.2$ & $39.0 \pm 7.3$ & $21.4,50.7$ \\
\hline V.G. $^{2}$ & Male & $(n=12)$ & Female & $(n=14)$ \\
\hline Age (years) & $65.1 \pm 5.0$ & $59.5,74.8$ & $61.33 \pm 5.07$ & $55.5,73.2$ \\
\hline Height (m) & $1.67 \pm 0.07$ & $1.56,1.80$ & $1.54 \pm 0.05$ & $1.43,1.61$ \\
\hline Weight (Kg) & $71.4 \pm 7.5$ & $57.1,84.0$ & $56.91 \pm 9.60$ & $55.50,73.20$ \\
\hline $\mathrm{BMI}\left(\mathrm{Kg} / \mathrm{m}^{2}\right)$ & $25.6 \pm 1.8$ & $21.5,28.4$ & $24.03 \pm 3.56$ & $17.94,29.72$ \\
\hline Impedance(ohm) & $565.2 \pm 47.9$ & $493.0,641.3$ & $621.3 \pm 46.6$ & $583.3,741.0$ \\
\hline FFM $_{\text {DXA }}(\mathrm{kg})^{3}$ & $50.9 \pm 3.5$ & $46.0,59.6$ & $35.7 \pm 4.4$ & $28.9,44.5$ \\
\hline $\mathrm{FM}_{\text {DXA }}(\mathrm{kg})^{3}$ & $19.2 \pm 5.0$ & $7.9,26.5$ & $20.6 \pm 6.8$ & $12.0,33.5$ \\
\hline BF\% ${ }_{D X A}(\%)^{3}$ & $27.0 \pm 5.3$ & $14.1,34.4$ & $35.8 \pm 6.7$ & $26.6,47.8$ \\
\hline
\end{tabular}

${ }^{1} \mathrm{MG}$ : Modeling group; ${ }^{2} \mathrm{VG}$ : Validation group; ${ }^{3} \mathrm{FFM}_{\mathrm{DXA}}, \mathrm{FM}_{\mathrm{DXA}}$ (fat free mass) and $\mathrm{BF} \%_{\mathrm{DXA}}$ (percentage of fat percentage) were measured by DXA. 


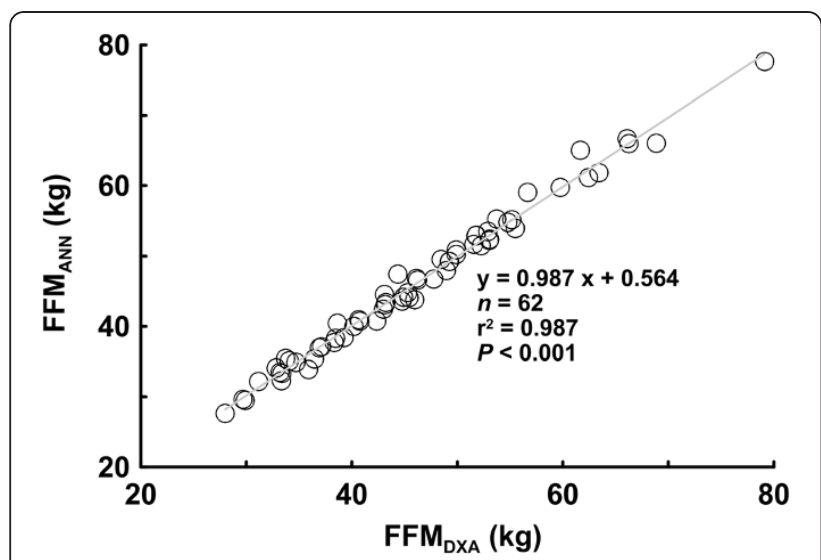

Figure 2 The relationship between the FFM values predicted by the BP-ANN model and the FFM values measured by DXA is shown for the modeling group.

limits of agreement for $\mathrm{FFM}_{\mathrm{ANN}}$ vs. $\mathrm{FFM}_{\mathrm{DXA}}$ was \pm 2.386 $\mathrm{kg}$ at $2 \mathrm{SD}$. The ranges of SEE in Eq. (4) $(\mathrm{SEE}=2.729 \mathrm{~kg})$ and in the optimal BP-ANN model (SD $=1.192 \mathrm{~kg}$ ) are identified in Figure 4a The Bland-Altman plot of the differences between the body fat percentages estimated by both Eq. (4) and the optimal BP-ANN model against FFM $_{\mathrm{DXA}}$ is shown in Figure 4b. The SD of bias in Eq. (4) was $3.850 \%$, while the SD of bias was $1.755 \%$ in the optimal BP-ANN model.

The $\mathrm{FFM}_{\mathrm{LR}}$ and $\mathrm{FFM}_{\mathrm{ANN}}$ estimated by the VG group vs. $\mathrm{FFM}_{\mathrm{DXA}}$ analysis were 0.933 and 0.963 , respectively. The above distributions are shown in Figure 5.

\section{Discussion}

To elucidate the predictive performance in estimating the body composition for the elderly by using the linear model and the optimal BP-ANN model, identical dataset were

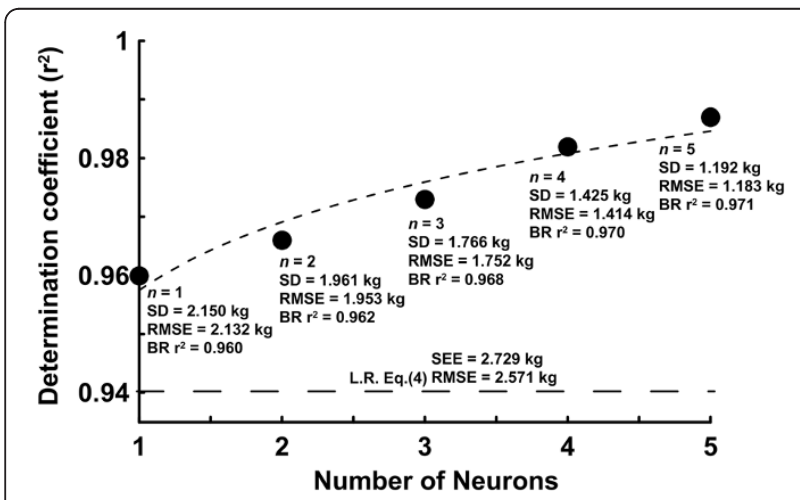

Figure 3 The relationship between the number of neurons in the input layer of the BP-ANN models and the determination coefficients of the FFM values measured by DXA are shown for the modeling group. $\mathrm{SD}$, standard deviation; RMSE, root mean square error; BR $r^{2}$, determination coefficients of predictive values by Bayesian Regularization and the FFM values measured by DXA. used to develop these two models for comparison. Using the anthropometric data, the BP-ANN model with the simple input layer with five neurons was adopted to predict the FFM and body composition of the elderly. For predicting the $\mathrm{FFM}_{\mathrm{DXA}}$, the coefficient of determination for the $\mathrm{FFM}_{\mathrm{ANN}}\left(\mathrm{r}^{2}=0.960\right)$ estimated by the BP-ANN model with a single neuron in the input layer was greater than that of the $\mathrm{FFM}_{\mathrm{LR}}$ estimated by the linear model $\left(\mathrm{r}^{2}=0.940\right)$. The presence of more neurons in the input layer of the weighted BP-ANN model resulted in a higher coefficient of determination; the $\mathrm{r}^{2}$ value reached up to 0.987 when the five neurons were included in the input layer of the BP-ANN model. As more variables were included in the ANN model the correlation coefficient between predictive value and $\mathrm{FFM}_{\mathrm{DXA}}$ increased, nearly approached to one. When compare the results with other studies using impedances in linear model, the FFM values for the elderly estimated by Genton et al. [33], Deurenberg et al. [34] and Roubenoff et al. [35] were underestimated approximately 2.9 to $7.1 \mathrm{~kg}$ in males and approximately 2.3 to $6.7 \mathrm{~kg}$ in females. Nevertheless, in comparison to the values determined by Baumgartner et al. [36], their results overestimated FFM roughly by $4.3 \mathrm{~kg}$ in males and approximately $1.4 \mathrm{~kg}$ in females. The data from Kyle et al. [37] show that the differences between the measured FFM and the DXA were $0.2 \pm 2.0 \mathrm{~kg}$ in males and $0.0 \pm 1.6 \mathrm{~kg}$ in females. Despite the acceptable coefficients of determination $\left(r^{2}=0.756-0.883\right)$ in the above-mentioned studies, improved $\mathrm{r}^{2}$ values were obtained in our five neurons input layer BP-ANN model. In particular, the smallest standard deviation of differences existed in the $\mathrm{FFM}_{\mathrm{ANN}}$ vs. $\mathrm{FFM}_{\mathrm{DXA}}$ comparison $(0.0 \pm 1.192 \mathrm{~kg})$.

Because a larger computing capacity and longer processing time were required to exert the arbitrary function mapping or non-linear function mapping, we optimized the training process in BP-ANN model by using the Levenberg-Marquardt Algorithm to improve the convergence. Despite the limits of memory resources [32], the space required for our analysis is a relatively tiny amount in modern computer hardware. That trend makes our technique more applicable. To prevent the occurrence of a local error minimum in our BP-ANN model, we repeatedly applied various random initial values to the training process for the BP-ANN model. Meanwhile, the trial calculations for the errors and the correlation coefficient fit the optimal BP-ANN model.

With the same training data, the accuracy and precision of the BP-ANN model are directly related to the number of neurons and hidden layers. To prevent overfitting in our BP-ANN model, the model was optimized by Bayesian Regularization. If the relationship between dependant variable and independent variables were linear, using BP-ANN model to develop linear prediction equation, with proper training similar or nearly identical 

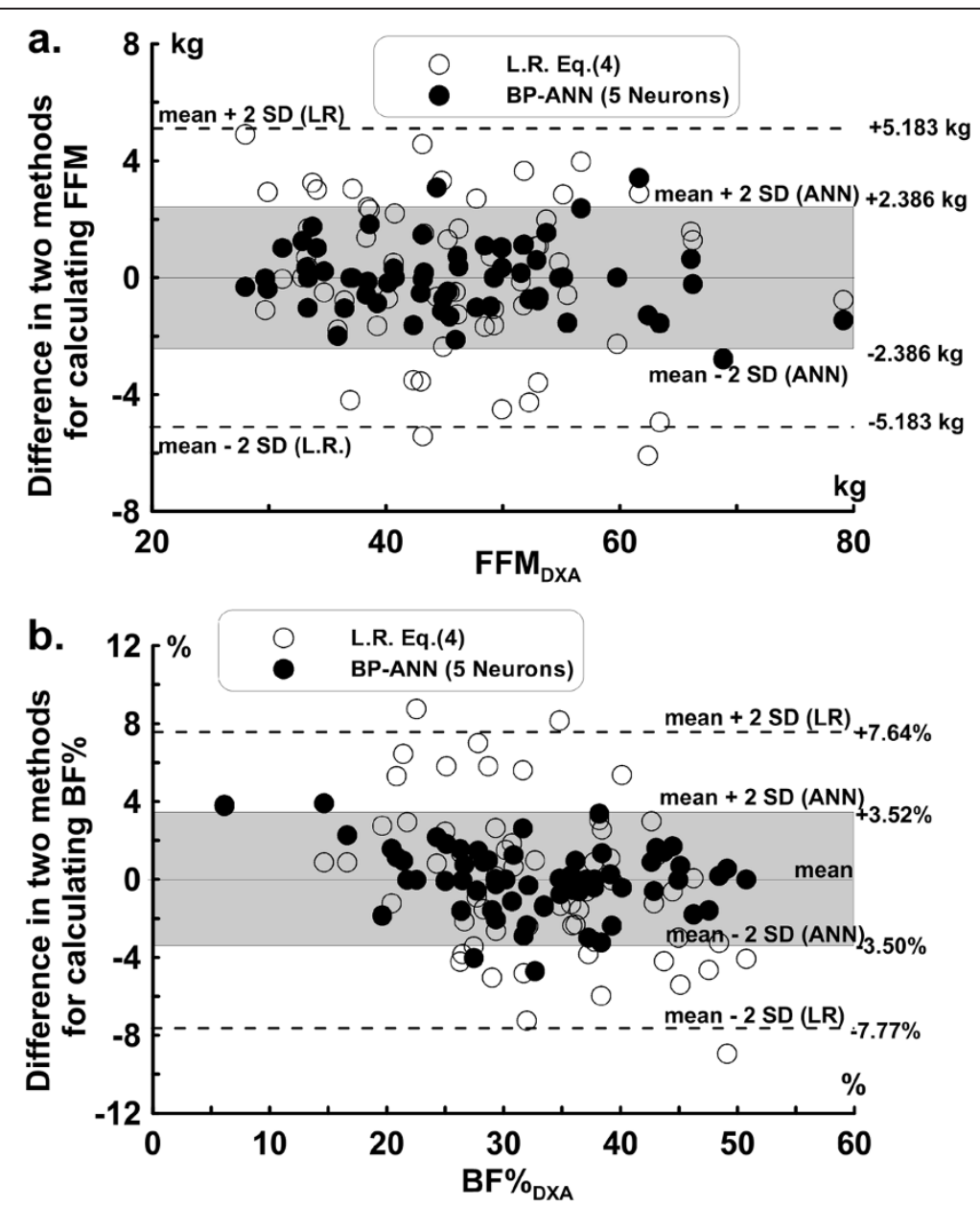

Figure 4 The differences (bias) in the predicted (a) FFM and (b) BF\% that are derived from both the linear prediction equations (LR) and the optimal BP-ANN (Back Propagation Artificial Neural Network) model are shown for the modeling group. The empty circles represent the values predicted by the linear prediction equations (LR), and the solid circles represent the values predicted by the BP-ANN (Back Propagation Artificial Neural Network) model.

results to linear regression may be achieved. However, if the relationship were non-linear, using linear regression model to construct prediction equation, the predictive accuracy will be limited [38]. When constructing a BPANN model, there was no guideline or rules for how many hidden layers should be constructed, how many neurons should be included, and how to choose proper transfer function for achieving the optimal predictive equation. For practical application, the different combination of layers and neurons may be used to construct model via training conjoin with validation analysis to achieve desired results. In most case, when the included hidden layers and neurons approach certain numbers, the estimated error will be minimized to certain value which cannot be reduced as more hidden layers and neurons are included into model. This phenomenon was observed as we constructed our model. For the minimum sample size, ANN model can generate better

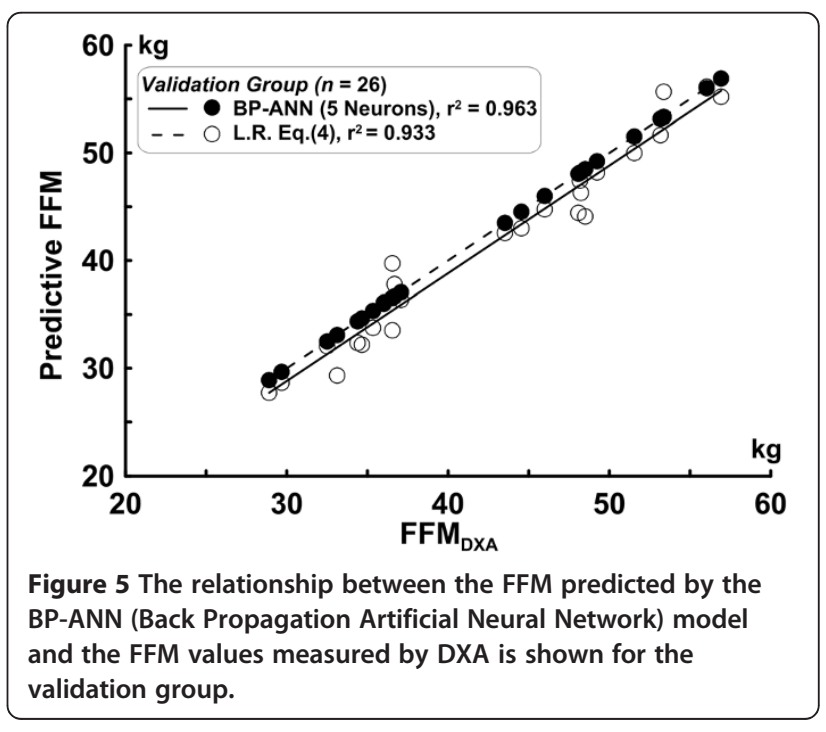


results than that of linear model when sample size is lower than 2000 [39]. But ANN model still has its downside, the estimated weight matrix, bias vector cannot have the same interence and interpretation as linear regression coefficient [40]. Another downside of ANN model is the complex calculation of the model which demand higher computation capability of measuring system or device, but recent development of computer hardware had made this obstacle easily be overcome which results in widely application of ANN model [41].

After ruling out other sources of dependent variability, the linear regression can easily describe the relationship between the single independent variable and the single major dependent variable. However, the linear regression does not work well in the systems with the dependent variables correlated with each others, especially in the complex human physiological system. Many variables, such as sex, age, physical activity, diet, genetics, weight and height, can affect body composition or have non-linear relationship among variables [18]. These variables may interact with each other to influence the estimation of body composition. In other words, the multiple dependent anthropometric variables may exhibit a coupled relationship rather than an independent linear relationship as assumed in a multiple linear regression model [42].

Consequently, the application of non-linear functions and other more flexible mathematic functions to describe the relationships between body composition parameter (fat free mass) and multiple variables requires much more attention to improve the predictive accuracy. In fact, the RMSE for FFM in our BP-ANN model was much lower than in LR model. Further evidence provided by Liu et al. shows that the application of the BIA system and the ANN model to estimating the FFM of the lower limbs exhibits greater performance than a linear model [43].

Many studies had successfully apply ANN model in clinical trials [22,24,27-31]. However, some indicated that ANN model can't perform better than linear regression model in clinical application. Therefore, the novel ANN model should be validated and use with care [39].

\section{Conclusions}

Collectively, our study comparing the differences between the $\mathrm{FFM}_{\mathrm{ANN}}$ and $\mathrm{FFM}_{\mathrm{LR}}$, the results of our study show superior outcomes with the BP-ANN model and indicate the successful application of this model in predicting the body composition of the elderly. The BP-ANN model may be incorporated into the measuring device for practical use in the future.

\section{Abbreviations}

BIA: Impedance analysis; FFM: Fat free mass; BF\%: body fat percentage; FM: Body fat mass; BP-ANN: Back propagation artificial neural network;
FFM $M_{L R}$ : FFM estimated with the analysis of linear regression model; FFM ANN: FFM estimated with the analysis of BP-ANN model; DXA: Dual-

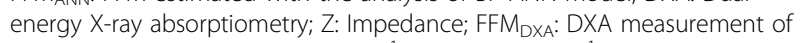
FFM; H: Height; M: Weight; S: Sex; $W_{i, j}^{1}$ : Weight matrix; $b_{i}^{1}$ : Bias vector; $f^{1}$ : Transfer function; SD: Standard deviation; $r^{2}$ : Determination coefficient; SEE: Standard estimation of error; RMSE: Root mean square error; BR $r^{2}$ : Determination coefficients of estimation values by Bayesian Regularization and the FFM $M_{D X A} ; B F \%_{D X A}$ : DXA measurement of body fat percentage; BF\% LR: BF\% estimated by BIA with the analysis of linear regression model;

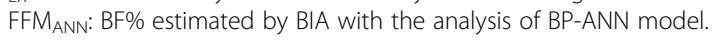

\section{Competing interests}

Charder Electronic Co., LTD funded this study. One author, Hsieh KuenChang, belongs to the Research Center of the company. The other authors have declared that they have no competing interests.

\section{Authors' contributions}

$\mathrm{KCH}$, the main author, contributed to the collection and interpretation of the BIA analysis data and developed the BP-ANN model; YJC completed the statistical analysis; YYC contributed to the collection and interpretation of the DXA analysis data and drafted the manuscript; HKL and YCH designed and revised the manuscript and assisted in the development of the BP-ANN model. All of the authors have read and approved the final manuscript.

\section{Acknowledgements}

This work was supported by grant NSC100-2410-H-H-028-MY3 from the National Science Council of Taiwan and grant CGR-A10001 from the Research Center of Charder Electronic Co., LTD.

\section{Author details}

${ }^{1}$ Research Center, Charder Electronic Co., LTD, Taichung, Taiwan.

2Department of Radiation Oncology, Mackay Memorial Hospital, Taipei, Taiwan. ${ }^{3}$ Sport Science Research Center, National Taiwan University of Physical Education and Sport, Taichung, Taiwan. ${ }^{4}$ Graduate Institute of Sport Coaching Science, Chinese Culture University, Taipei, Taiwan. ${ }^{5}$ Department of Physical Education, National Taiwan University of Physical Education and Sport, 16, Sec. 1, Shuan-Shih Rd, Taichung 40404, Taiwan.

Received: 26 July 2012 Accepted: 22 January 2013

Published: 6 February 2013

\section{References}

1. Corrada MM, Kawas CH, Mozaffar F, Paganini-Hill A: Association of body mass index and weight change with all-cause mortality in the elderly. Am J Epidemiol 2006, 163:938-949.

2. Wannamethee SG, Shaper AG, Lennon L, Whincup PH: Decreased muscle mass and increased central adiposity are independently related to mortality in older men. Am J Clin Nutr 2007, 86:1339-1346.

3. Meeuwsen S, Horgan GW, Elia M: The relationship between BMI and percent body fat, measured by bioelectrical impedance, in a large adult sample is curvilinear and influenced by age and sex. Clin Nutr 2010, 29:560-566.

4. Kuczmarski RJ: Need for body composition information in elderly subjects. Am J Clin Nutr 1989, 50:1150-1157.

5. Ferrara S, Pazzucconi F, Bondioli A, Mombelli G, Agrati A, Ferraro G, Zoppi F, De Rosa C, Calabresi L, Sirtori CR: Development of a model based on body composition to predict drug kinetics: II. Application of the model to the use of digoxin in elderlies. Pharmacol Res 2004, 50:105-108.

6. Bussolotto M, Ceccon A, Sergi G, Giantin V, Benincà P, Enzi G: Assessment of body composition in elderly: accuracy of bioelectrical impedance analysis. Gerontology 1999, 45:39-43.

7. Kyle UG, Bosaeus I, De Lorenzo AD, Deurenberg P, Elia M, Gómez JM, Heitmann BL, Kent-Smith L, Melchior JC, Pirlich M, Scharfetter H, Schols AM, Pichard C, Composition of the ESPEN Working Group: Bioelectrical impedance analysis part I: review of principles and methods. Clin Nutr 2004, 23:1226-1243.

8. Svendsen OL, Haarbo J, Heitmann BL, Gotfredsen A, Christiansen C: Measurement of body fat in elderly subjects by dual-energy $\mathrm{x}$-ray absorptiometry, bioelectrical impedance, and anthropometry. Am J Clin Nutr 1991, 53:1117-1123.

9. Nuñez C, Gallagher D, Visser M, Pi-Sunyer FX, Wang Z, Heymsfield SB: Bioimpedance analysis: evaluation of leg-to-leg system based on pressure contact footpad electrodes. Med Sci Sports Exerc 1997, 29:524-531. 
10. Lukaski HC, Siders WA: Validity and accuracy of regional bioelectrical impedance devices to determine whole-body fatness. Nutrition 2003, 19:851-857.

11. Lloret Linares C, Ciangura C, Bouillot JL, Coupaye M, Declèves X, Poitou C, Basdevant A, Oppert JM: Validity of leg-to-leg bioelectrical impedance analysis to estimate body fat in obesity. Obes Surg 2011, 21:917-923.

12. Dehghan $M$, Merchant AT: Is bioelectrical impedance accurate for use in large epidemiological studies? Nutr J 2008, 7:26

13. Boneva-Asiova Z, Boyanov MA: Body composition by leg-to-leg bioelectrical impedance and dual-energy X-ray absorptiometry in nonobese and obese individuals. Diabetes Obes Metab 2008, 10:1012-1018.

14. Unick JL, Utter AC, Schumm S, Mcnnis T: Evaluation of leg-to-leg BIA in assessing body composition in high-school-aged males and females. Res Sports Med 2006, 14:301-313.

15. Civar S, Aktop A, Teran E, Ozdol Y, Ozer K: Validity of leg-to-leg bioelectrical impedance measurement in highly active women. J Strength Cond Res 2006, 20:359-365.

16. Svantesson U, Zander M, Klingberg S, Slinde F: Body composition in male elite athletes, comparison of bioelectrical impedance spectroscopy with dual energy X-ray absorptiometry. J Negat Results Biomed 2008, 7:1.

17. Cheng B, Titterington DM: Neural networks: A review from statistical Perspective. Statist Sci 1994, 9(1):2-30.

18. Linder R, Mohamed El, De LA, Poppl SJ: The capabilities of artificial neural networks in body composition research. Acta Diabetol 2003, 40:59-S13.

19. McCullagh P, Nelder JA: Generalized linear models. 2nd edition. London: Champan and Hall; 1989.

20. Cox DR: Regression models and life tables. J Roy Statist Soc Ser B 1972, 34:187-220

21. Wasson JH, Sox HC, Neff RK, Goldman L: Clinical prediction rules: Applications and methodological standards. N Engl J Med 1985, 313:793-799.

22. Baxt WG: Application of artificial neural network to clinical medicine. Lancet 1995, 346:1135-1138.

23. Baxt WG: Use of an artificial neural network for data analysis in clinical decision-making: the diagnosis of acute coronary occlusion. Neural Comput 1990, 2:480-489.

24. Penedo MG, Carreira MJ, Mosquera A, Cabello D: Computer-aided diagnosis: a neural-network-based approach to lung nodule detection. IEEE Trans Med Imag 1998, 17:872-880.

25. Devine B, Macfarlane PW: Detection of electrocardiographic 'left ventricular strain' using neural nets. Med Biol Eng Comput 1993, 31:343-348.

26. Dybowskir R, Gant V: Artifical neural networks in pathology and medical laboratories. Lancet 1995, 346:1203-1207.

27. Veng-Pedersen P, Modi NB: Application of neural networks to pharmacodynamics. J Pharm Sci 1993, 82:918-926.

28. DiRusso SM, Sullivan T, Holly C, Cuff SN, Savino J: An artificial neural network as a model for prediction of survival in trauma patients: validation for a regional trauma area. J Trauma 2000, 49:212-223.

29. Izenberg SD, Williams MD, Luterman A: Prediction of trauma mortality using a neural network. Am Surg 1997, 63:275-281.

30. Chiu JS, Chong CF, Lin YF, Wu CC, Wang YF, Li YC: Applying an artificial neural network to predict total body water in hemodialysis patients. Am J Nephrol 2005, 25:507-513.

31. Mohamed El, Maiolo C, Linder R, Pöppl SJ, De Lorenzo A: Predicting the intracellular water compartment using artificial neural network analysis. Acta Diabetol 2003, 40:S15-S18.

32. Hagan MT, Demuth HB, Beale M: Neural Network Design. Inc: Thomson Learning: 1996.

33. Genton L, Karsegard VL, Kyle UG, Hans DB, Michel JP, Pichard C: Comparison of four bioelectrical impedance analysis formulas in healthy elderly subjects. Gerontology 2001, 47:315-323.

34. Deurenberg P, van der Kooij K, Evers P, Hulshof T: Assessment of body composition by bioelectrical impedance in a population aged greater than 60 y. Am J Clin Nutr 1990, 51:3-6.

35. Roubenoff R, Baumgartner RN, Harris TB, Dallal GE, Hannan MT, Economos CD, Stauber PM, Wilson PW, Kiel DP: Application of bioelectrical impedance analysis to elderly populations. J Gerontol A Biol Sci Med SC 1997, 52:M129-M136.

36. Baumgartner RN, Heymsfield SB, Lichtman S, Wang J, Pierson RN Jr: Body composition in elderly pople: Effect of criterion estimates on predictive equations. Am J Clin Nutr 1991, 53:1345-1353.
37. Kyle UG, Genton L, Karsegard L, Slosman DO, Pichard C: Single prediction equation for bioelectrical impedance analysis in adults aged 20-94 years. Nutrition 2000, 17:248-253.

38. Burke HB, Goodman P, Rosen DB, Henson D, Weinstein JN, Harrel FE Jr, Marks JR, Winchester DP, Bostwick DG: Arficial neural network improve the accuracy of cancer survival prediction. Cancer 1997, 79:857-862

39. Sarqent DJ: Comparison of artificial neural networks with other statistical approaches: results from medical data sets. Cancer 2001, 91:1636-1641.

40. Warner B, Misra M: Understanding Neural Networks as Statistical Tools. Am Stat 1996, 50:284-293.

41. Larkin M: Arficicial intelligence slips cautiously into the clinic. Lancet 2001, 358:898.

42. Roubenoff R, Dallal GE, Wilson PW, Predicting body fatness: The body mass index vs estimation bioelectrical impedance. Am J Public Health 1995, 85:726-728.

43. Liu TP, Kao MF, Jang TR, Wang CW, Chung CL, Chen J, Chen YY, Hsieh KC: New application of bioelectrical impedance analysis by the back propagation artificial neural network mathematically predictive model of tissue composition in the lower limbs of elderly people. Int J Geron 2012, 6:20-26.

doi:10.1186/1475-2891-12-21

Cite this article as: Hsieh et al:: The novel application of artificial neural network on bioelectrical impedance analysis to assess the body composition in elderly. Nutrition Journal 2013 12:21.

\section{Submit your next manuscript to BioMed Central and take full advantage of:}

- Convenient online submission

- Thorough peer review

- No space constraints or color figure charges

- Immediate publication on acceptance

- Inclusion in PubMed, CAS, Scopus and Google Scholar

- Research which is freely available for redistribution
C Biomed Central 